\title{
USING TEXTILE ARAMID FABRICS TO INCREASE THE BALLISTIC RESISTANCE OF ULTRA-HIGH-PERFORMANCE STEEL-FIBRE REINFORCED CONCRETE
}

\author{
Michal Mára, Radoslav SovjáK*， JindŘich FornŮSEK \\ Czech Technical University in Prague, Faculty of Civil Engineering, Experimental Centre, Thákurova 7, 16629 \\ Prague, Czech Republic \\ * corresponding author: sovjak@fsv.cvut.cz
}

\begin{abstract}
Thin plates made of Ultra-High-Performance Steel-Fibre-Reinforced Concrete (UHPSFRC) with textile Aramid fabrics were subjected to a projectile impact and its post-test damage was discussed. The damage degrees were the type of the response and crater surface, which was determined by using a 3D scanner. The most common type of ammunition, which is a $7.62 \times 39 \mathrm{~mm}$ calibre with a full-metal jacket and a mild-steel core, was used for all specimens.

It was verified experimentally that the UHP-SFRC with textile Aramid fabrics has a better ballistic performance in comparison with its counterpart made of the UHP-SFRC without any textile reinforcement. Also, it was verified that specimens with the point or segment interconnection threads between the front side textile fabrics and rear side textile fabrics have a higher resistance due to the better integrity of the monolithic UHP-SFRC mixture.
\end{abstract}

KEywords: Concrete, fibres, textile, Aramid fabrics, projectile impact, thin plates.

\section{INTRODUCTION}

This work aims to compare the ballistic resistance and the size of the crater area of Ultra-High-Performance Steel-Fibre-Reinforced Concrete (UHP-SFRC) with and without textile Aramid fabrics under a projectile impact. The data derived from this study can be used to increase the ballistic resistance of existing structures and new buildings that belong to the category of defence and critical infrastructure. It is important to note that many protective buildings provide the last layer of defence against the extreme load event when all other protective measures have failed and this load action is projected onto a structure. Attackers can use many types of weapon systems and such events cannot be always predicted beforehand. Using the right information and risk assessment can provide effective measures to mitigate the consequences of such incidents [1].

The Ultra-High-Performance Steel-Fibre-Reinforced Concrete with dispersing steel fibres seems to be one of the highly promising materials, which can be used in these cases [2 6]. This emerging composite material has increased compressive strength and enhanced ductility, which benefits mainly from the randomly distributed fibres [7] 10]. Steel, glass or polymer fibres are usually used to increase the ductility of the resulting mixtures [11-13]. Previous studies have shown that the optimal fibre content for thin targets concerning the in-service projectile impact lies around $2.0 \%$ by volume [14, 15]. The purpose of this contribution was to extend a previous case studies and find the optimal arrangement of the textile reinforcement for the ballistic resistance against the high-speed projectile impact.

When the projectile hits the specimen's body, it generates a pressure wave that propagates through the material body. The pressure is reflected from the rear side of the slab and generates tensile stresses on the distal face of the target. Here, if the tensile strength is less than the resulting tensile stresses, scabbing occurs instantly. Since the propagation of the pressures wave occurs at the speed of sound, the scabbing precedes the penetration of the bullet. Here, the resistance thickness is reduced instantly due to the aforementioned scabbing. This study, therefore, aims to increase the tensile capacity of the UHPSFRC by an application of the textile Aramid fabrics to suppress the scabbing from the distal face of the target and to increase the overall ballistic resistance of the protective element.

Aramid is a lightweight, high-strength, impactresistant fabric, which is well suited for the application as a back-face lining. Due to its light weight, there is no significant increase in the weight of the resulting protective structure. Several pieces of research recommended Aramid as a suitable material for concrete elements to increase its capacity under quasistatic loading [16, 17]. Besides, Kim et al. 18] tested macro-aramid-fibre-reinforced cementitious composites (AR-FRCCs) as well as textile-reinforced cementitious composites with a $3 \mathrm{D}$ spacer fabric at high strain rates. Kim et al. noted that even though the 3D-TRCCs produced a higher energy absorption capacity than the AR-FRCCs, the energy absorption capacity of the 3D-TRCCs decreased at strain rates higher than $100 \mathrm{~s}^{-1}$ [18]. 


\begin{tabular}{lcc}
\hline Components & $\mathrm{kg} / \mathrm{m}^{3}$ & $\begin{array}{c}\text { Proportions } \\
\text { by weight }\end{array}$ \\
\hline Cement CEM I 52.5 R & 695 & 1 \\
Admixtures & 270 & 0.39 \\
Fine sands & 1225 & 1.76 \\
Water & 165 & 0.24 \\
Plasticizers & 40 & 0.06 \\
Steel fibres & 120 & 0.17 \\
\hline
\end{tabular}

TABLE 1. UHP-SFRC composition.

The main idea behind the application of the fabrics is, firstly, to reinforce the distal face of the target to increase the tensile capacity and, secondly, to reinforce the proximal face of the plate to decrease the spalling from the compaction of the material during the impact.

This contribution aims to find the best performing layout arrangement in terms of various stitching of the Aramid fabric concerning its performance under the projectile impact. Three basic fabrics arrangements in terms of layer connection were tested and compared. These were point stitching, segment stitching and line stitching. The main damaged degrees through which the specimens were compared were the response type and area of the crater made by the aforementioned projectile impact.

\section{MAterial}

Ultra-High-Performance Steel-Fibre-Reinforced Concrete with a maximal grain size of $4 \mathrm{~mm}$ was used. The mixture contained a cement grade CEM I 52.5 R and the water-cement ratio was set to 0.24 . The composition of this mixture can be seen in Table 1

A specific mixing and dosing procedure adopted from previous studies [19, 20] were followed during the production. Microsilica and silica fine sands were added to the mixer first, and homogenized for 5 minutes. In the second step, cement and silica powder was added and the mixture was stirred for an additional 5 minutes. Finally, water, superplasticizers and fibres were added and the mixture was stirred for another 5 minutes. The amount of applied fibres was determined to be $1.5 \%$ by volume of the mixture. This particular volumetric content of fibres was found to the be most reasonable in terms of workability and the resulting performance of the hardened composite [14, 21]. The tensile strength of the brass-coated steel fibres was up to $3000 \mathrm{MPa}$, as specified by the manufacturer. The fibres were straight with a diameter and length of $0.13 \mathrm{~mm}$ and $14 \mathrm{~mm}$, respectively, and having an aspect ratio of $108: 1$. The mixtures offered very good workability, so the fresh mixture was placed in the middle of the mould and let to naturally flow and fill the mould. This led to the fibres being oriented along the sides of the mould. No other technique was used for the placement of the fresh mixture. It is assumed that the fibres in the concrete specimens

\begin{tabular}{lcc}
\hline Days after casting & $f_{t}(\mathrm{MPa})$ & $f_{c}(\mathrm{MPa})$ \\
\hline 1 day & 7.6 & 75.6 \\
7 days & 21.8 & 138.8 \\
28 days & 30.2 & 153.1 \\
\hline
\end{tabular}

TABLE 2. Mechanical properties of the UHP-SFRC mixture.

\begin{tabular}{lcc}
\hline $\begin{array}{c}\text { Type } \\
\text { of fabrics }\end{array}$ & $\begin{array}{c}\text { Number } \\
\text { of layers }\end{array}$ & Stitching \\
\hline P-221 & 1 & Point threads \\
G-154 & 2 & Line \\
D-2155 & 2 & Segment \\
D-2255 & 2 & Point threads \\
\hline
\end{tabular}

TABLE 3. Detailed information about Aramid fabrics.

are uniformly spread in the matrix. In case the fibres are oriented in the direction of tensile stress, better properties and usage for a loaded construction can be provided.

The slab specimens for ballistic tests were $300 \times$ $400 \mathrm{~mm}$ in size and thickness was designed to be $50 \mathrm{~mm}$. Slabs were removed from the mould 24 hours after the casting and left in the water tank at $20^{\circ} \mathrm{C}$ for 27 days. The average mechanical properties of the mixture, such as flexural strength $f_{t}$ and compressive strength $f_{c}$, were measured in 1, 7 and 28 days (Tab. 2). Mechanical properties were measured on prismatic samples with dimensions $40 \mathrm{~mm} \times 40 \mathrm{~mm} \times 160 \mathrm{~mm}$. All tests were performed on hydraulic testing machine DSM2500-100 or ZUZ-200 with a closed-loop deformation control system with a maximal capacity of $2500 \mathrm{kN}$ and $200 \mathrm{kN}$, respectively, available at the Experimental Centre following standard procedures prescribed in the national standard for testing hardened concrete.

Four different types of Aramid fabrics with a density of $1440 \mathrm{~kg} / \mathrm{m}^{3}$ and the average modulus of elasticity of 3.9 MPa were used. All fabrics were composed of the front and the rear side, which was interconnected by different types of stitches. The point, segment and line stitchings were used. Figure 1 shows a fabric in which both sides were connected across the entire cross-section by the line stitching. Figure 2 shows a fabric with the segment stitching where the edges of the connection were made by a line connection but the central part was connected by individual threads. Figure 3 shows the connection of both sides by one point stitching. The Aramid fabric was set into the mould (Figure 4) and then the UHP-SFRC mixture was poured. The detailed information on Aramid fabrics is shown in Table 3 .

\section{Testing}

The ballistic resistance was tested on 18 slabs made of UHP-SFRC and 12 of them were reinforced with 


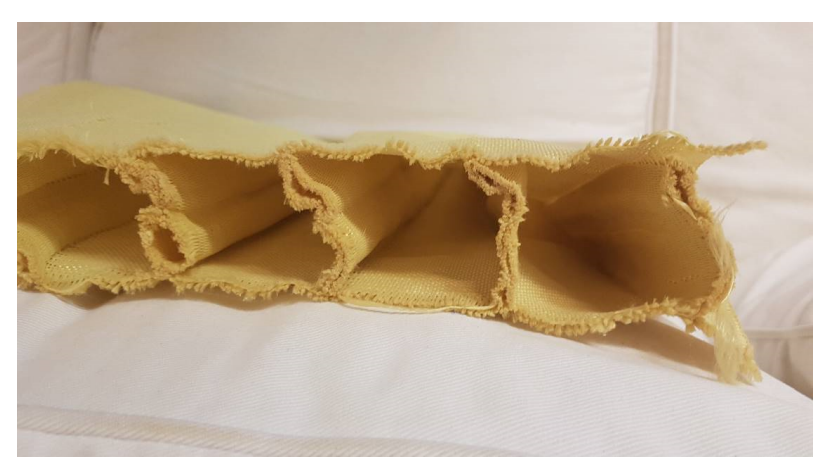

Figure 1. Aramid fabric with full line stitching.

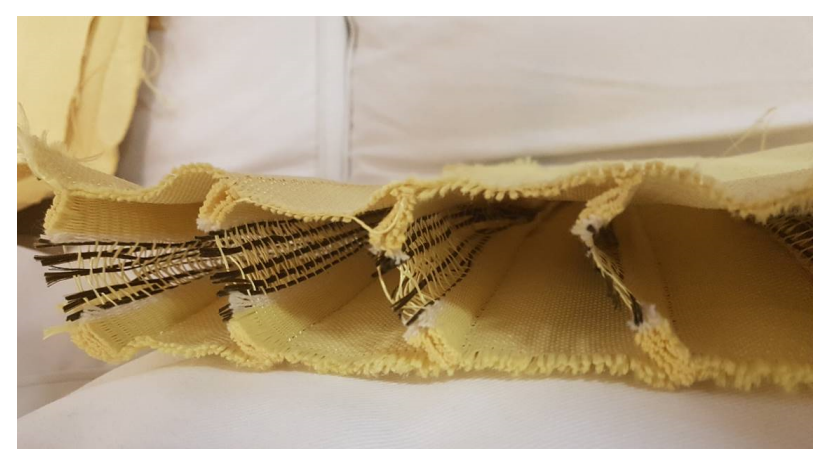

Figure 2. Aramid fabric with segment stitching.

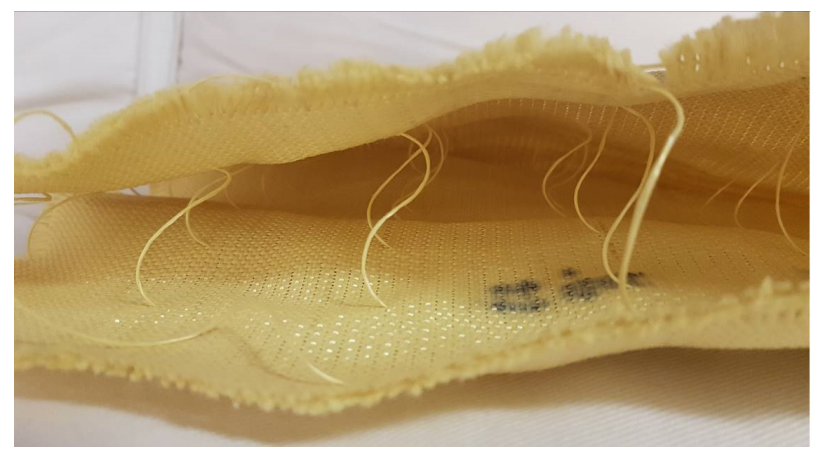

FiguRE 3. Aramid fabric with point stitching.

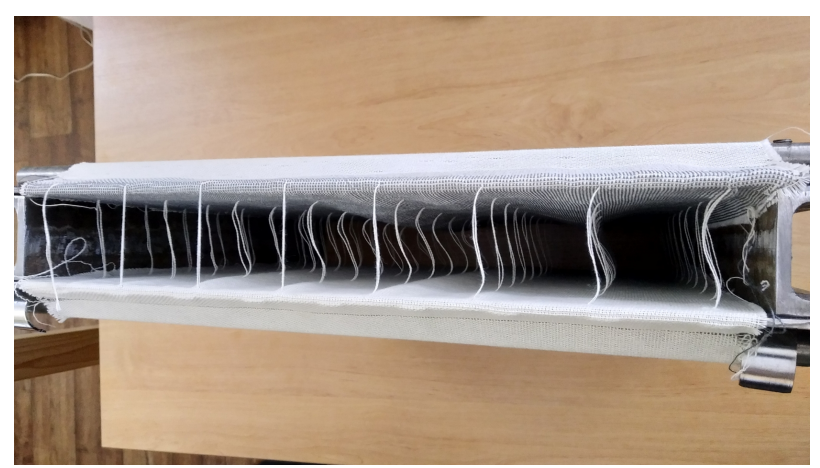

Figure 4. Aramid fabrics in the mould ready to be concreted. the textile Aramid fabrics. Three slabs were tested for each type of the fabric.

The experimental setup of ballistic tests was taken from previous studies [15, 20-22] as follows: each UHPSFRC plate was loaded in a special steel mount to position the targets against the shooter and to prevent any movement of the specimen during the ballistic impact. The mount was provided with eight screws, $20 \mathrm{~mm}$ in diameter, that were holding the UHP-SFRC plate at the corners from both sides, approximately $50 \mathrm{~mm}$ from both edges, thus simulating point supports (Fig. 5). Each UHP-SFRC plate specimen was placed in the mount and the FMJ-MSC projectile hit the centre of the specimen under a slight oblique angle, around $3^{\circ}$, which was considered as negligible (Fig. 6). The distance between the specimen and the shooter was 20 meters to ensure the safety of the shooter against the possible backward fragmentation from the target.

The impact was simulated as a hit of in-service $7.62 \times 39 \mathrm{~mm}$ full metal jacket ammunition with a mild-steel core, noted as a non-deformable projectile. The details of the projectile can be found elsewhere [15. 21, 23, 24. Briefly, the projectile consisted of a mildsteel core $(3.65 \mathrm{~g})$, steel jacket $(4.15 \mathrm{~g})$ and led tip $(0.24 \mathrm{~g}) 22$. The yield strength of the mild-steel core was experimentally determined to be $550 \mathrm{MPa}$ and the overall weight of the ogive-nose shaped steel jacketed projectile was 8.04 grams. The length of the nondeformable projectile was $26.7 \mathrm{~mm}$ and the diameter of the projectiles and the mild steel core was $7.92 \mathrm{~mm}$ and $5.68 \mathrm{~mm}$, respectively [24] (Fig. 7). It is important to mention that the steel jacket was stripped from the projectile during the penetration process and only the mild steel core penetrated through the UHP-SFRC material body.

The projectile was fired from a semiautomatic rifle CZ 858, calibre $7.62 \times 39 \mathrm{~mm}$, which is a civilian version of the former Czechoslovak military assault rifle SA-58. The ammunition is approved for civilian use. The muzzle velocity of each projectile was verified by a shooting chronograph that was located approximately 1 metre from the gun muzzle and values were in the range between 680 to $720 \mathrm{~m} / \mathrm{s}$ [15, 23. The impact velocity of the bullet was, according to the Kneubuehl 25], about $22 \mathrm{~m} / \mathrm{s}$ slower than the muzzle velocity.

One hit by the semi-automatic rifle CZ 858 was performed into the centre of each slab. The steel jacket was, in most cases, stripped from the core of the missile. The steel jacket was deformed and bounced back from the slab with a negligible velocity. The mildsteel core was the main element, which penetrated through the material body (Fig. 8).

The response type was classified following the convention used in Vossoughi [26, which has also been used in previous studies [14, 20] and contains four basic modes: perforated - $\mathrm{P}$ (the projectile passed through the specimen entirely); perforation limit - PL 


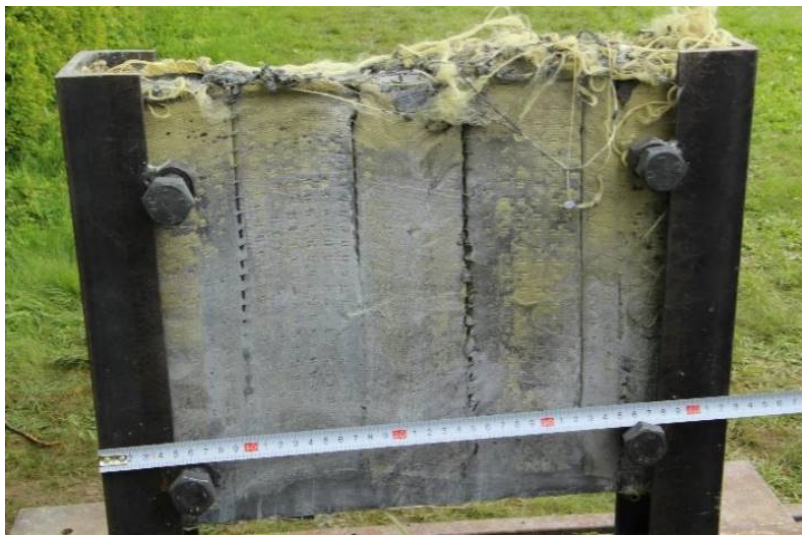

FIGURE 5. Special steel mount with embedded UHPSFRC thin plate $300 \times 400 \mathrm{~mm}$ in dimensions with applied Aramid fabrics.
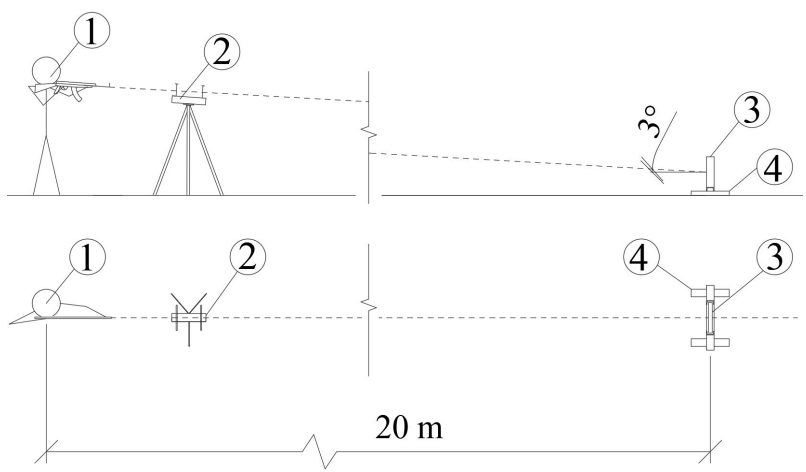

Figure 6. Ballistic test setup: (1) shooter, (2) shooting chronograph, (3) UHP-SFRC specimen, (4) special steel mount for the specimen [20].

(projectile was stuck); perforated and then bounced - PB (the projectile went through the slab and then bounced back) and unperforated - UP (the panel was punched but the projectile bounced back) [26].

\section{Scanning of the Damage}

The post-test damage of the specimens was scanned from both sides by a 3D scanner based on the photogrammetric principle (Fig. 9). The scanner was placed at a suitable distance and the resolution of the dual-camera was set and the damaged surface was scanned. Four to six scans were required for each slab to gain a complete $3 \mathrm{D}$ model with $1.8 \times 10^{6}$ to $2.4 \times 10^{6}$ captured points (Fig. 10). The measured data were processed and evaluated in the scan software. First, the model had to be localized to a crater created by a projectile impact (Fig. 11). Projections, errors and reflections were removed from the model to sufficiently determine the crater surface area (Tab. 4 .

\section{Results And Discussion}

The average results of the surface areas of craters that were obtained by using the 3D software are shown in Table 4. The measured data in a graph (Fig. 12) show a comparison between specimens with different

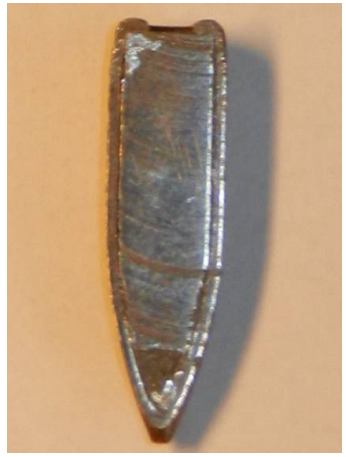

(A).

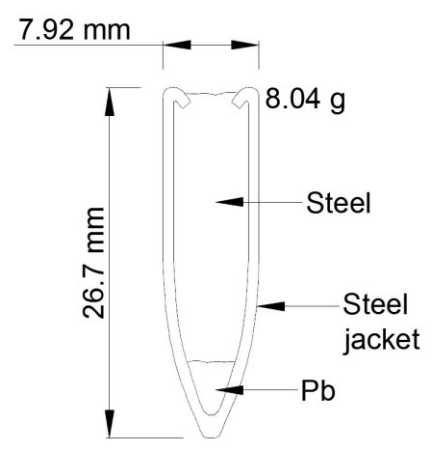

(B).
Figure 7. A) FMJ-MSC in-service projectile, calibre $7.62 \times 39 \mathrm{~mm}$ and B) its dimensions.

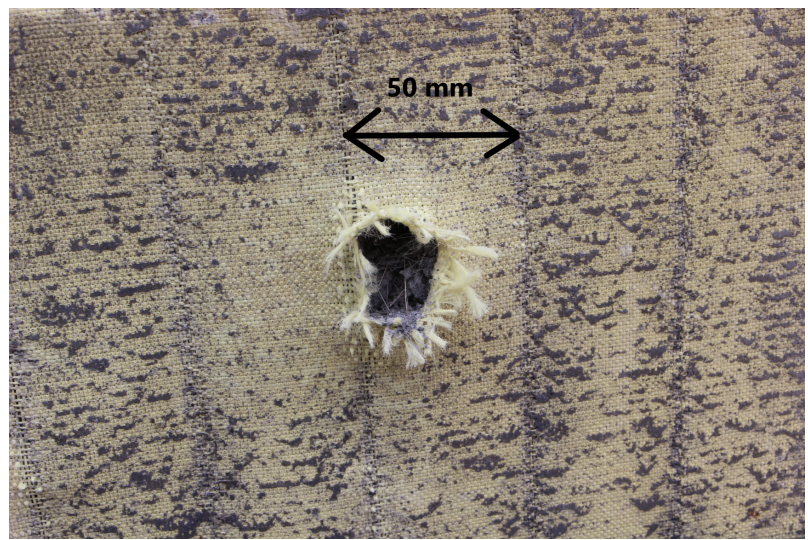

Figure 8. Post-test view on the proximal face of the UHP-SFRC slab with applied Aramid fabrics.

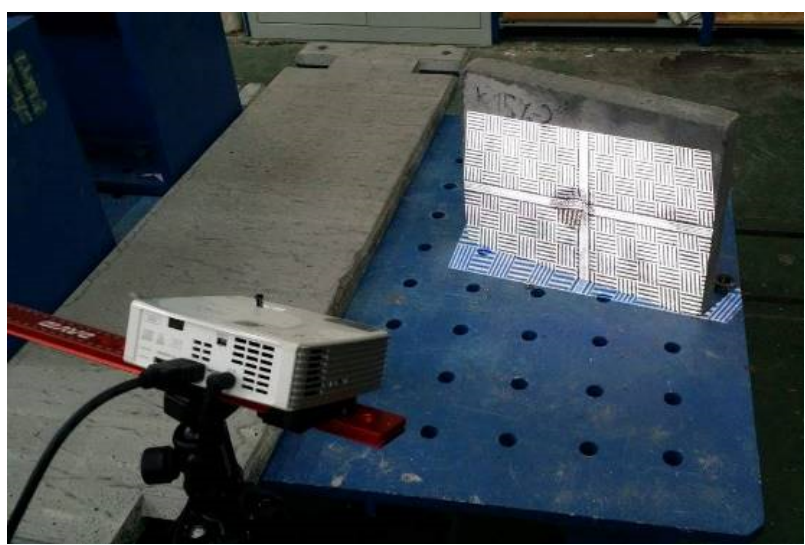

Figure 9. Post-test view on the proximal face of the UHP-SFRC slab with applied Aramid fabrics. 


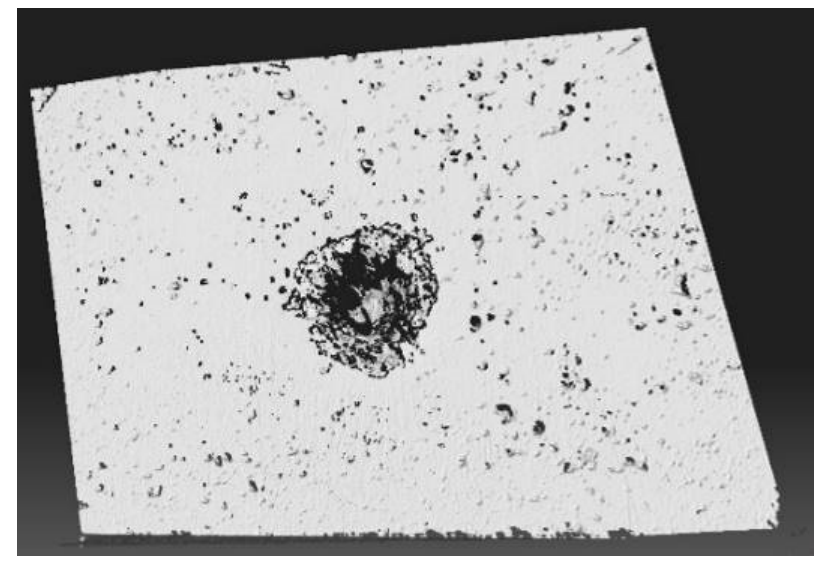

Figure 10. Post-test 3D model of the slab.

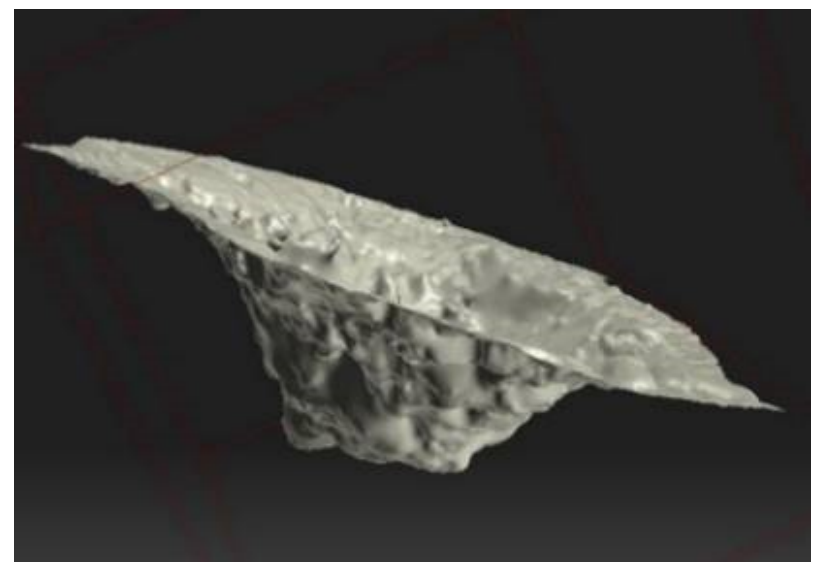

FIGURE 11. Visualization of the crater.

types of the textile Aramid fabrics (No. 2 - No. 5) and the UHP-SFRC reference specimens (No. 1). It can be seen that the projectile impact created a smaller front side crater on the specimens with the Aramid fabrics in comparison with the specimens without the Aramid fabrics. Table 4 also shows that the Aramid reinforcement may decrease the average value of the front crater surface by $33 \%$ compared to the UHPSFRC counterparts without any textile Aramid fabrics. All Aramid reinforced specimens were not penetrated except for one. One of the three specimens with the fabric P-221 was perforated and the average front crater surface was almost $9 \%$ higher than that of the G-154. The differences between the other specimens with two layers of fabric were no more than $442 \mathrm{~mm}^{2}$. These differences were caused by a type of stitching. It was found that the best way, in terms of a ballistic performance, is to bond the threads at one point. The specimens, which were bonded by the liner thread, had a higher crater surface because of the reduced monolithic integrity and a significant delamination that was observed around the line interconnections.

It was verified experimentally that an application of the textile Aramid fabrics increases the ballistic resistance of the UHP-SFRC in terms of perforation. When 2 layers of the textile fabrics were applied, no perforation occurred and, with a suitable type of in-

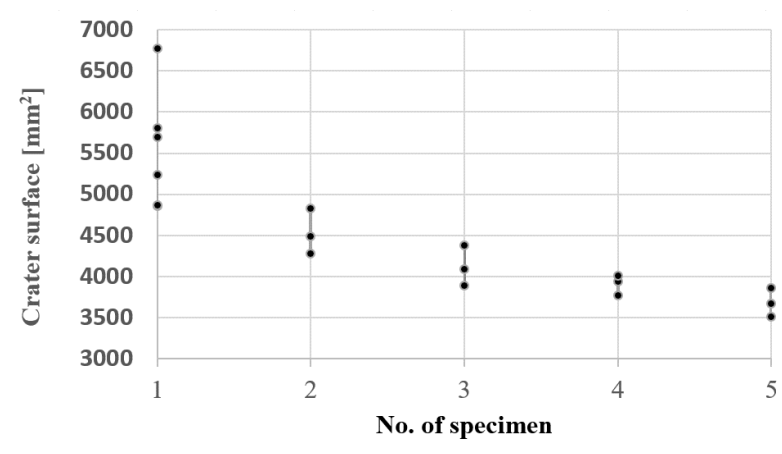

Figure 12. Crater surface on the front side for different types of fabrics.

terconnection between the proximal and distal face of the target, the front face crater surface decreases. This is due to the enhanced capacity of the slab, that is provided by an Aramid fabric on both sides of the plate. The increased tensile capacity is very helpful as very high tensile stresses occur when the stress wave is reflected from the distal face of the plate. This is demonstrated by the fact that no perforation occurred when 2 layers of textile fabrics were applied on the UHP-SFRC plate.

Therefore, it can be stated that is possible to further increase the penetration resistance of the UHP-SFRC with a minimal increment of the weight. However, it is important to note that the increased penetration resistance, while keeping the same weight of the plate, will be accompanied by a higher price due to the utilization of the textile Aramid fabrics.

\section{CONCLUSiOnS AND FURTHER OUTLOOK}

The major aim of this paper was to investigate the ballistic resistance of the UHP-SFRC reinforced with Aramid fabrics. It was found that the specimens with the fabric reinforcement could dissipate energy better and the projectile impact causes less damage in comparison to the UHP-SFRC samples without Aramid fabrics. Furthermore, the damage was more localized, therefore, the residual strength is probably higher. It was verified experimentally that the ballistic resistance of the UHP-SFRC plate with the point-stitching Aramid fabric behaves better than its segment and full-line stitching counterparts. The integrity of the slab was significantly increased when the point stitching was applied, as the cementitious material was significantly more interconnected over the specimen body. The results derived in this study can be used to increase a ballistic resistance of protective structures.

Nowadays, it is assumed that the steel fibres are distributed uniformly in the concrete over its volume with a random alignment. The position of fibres is affected by many factors. For instance, by the shape of the mould, the fluidity of the mixture, casting methods and many others. Consequently, to determine the exact position of the fibres is difficult. By positioning 


\begin{tabular}{lccccccc}
\hline \multirow{2}{*}{ No. } & \multirow{2}{*}{$\begin{array}{c}\text { Type } \\
\text { of fabrics }\end{array}$} & \multirow{2}{*}{$\begin{array}{c}\text { Number } \\
\text { of layers }\end{array}$} & $\begin{array}{c}\text { Response } \\
\text { type }\end{array}$ & $\begin{array}{c}\text { Front side/Proximal face } \\
\text { Average }\end{array}$ & SD & Rear side/Distal face \\
Average & SD \\
\hline 1 & - & - & $\mathrm{P}$ & 5542 & 723 & 4688 & 666 \\
2 & $\mathrm{P}-221$ & 1 layer & $\mathrm{P}^{*} / \mathrm{UP}$ & 4528 & 277 & $4023^{*}$ & $2323^{*}$ \\
3 & $\mathrm{G}-154$ & 2 layers & $\mathrm{UP}$ & 4121 & 248 & 0 & 0 \\
4 & $\mathrm{D}-2155$ & 2 layers & $\mathrm{UP}$ & 3907 & 126 & 0 & 0 \\
5 & $\mathrm{D}-2255$ & 2 layers & $\mathrm{UP}$ & 3679 & 174 & 0 & 0 \\
\hline
\end{tabular}

* The crater surface on the rear side was measured on only one slab. The others were undamaged on the rear side.

TABLE 4. Crater surface of specimens after projectile impact.

the fibres in the direction of the tensile stress, the maximum efficiency is provided. One of the future challenges in terms of increasing the ballistic resistance would be aimed towards the targeted orientation of steel fibres in the cement matrix where it is possible to provide the requested position and direction of fibres, solving the main problem of the design.

\section{ACKNOWLEDGEMENTS}

The authors gratefully acknowledge the financial support from the Czech Science Foundation (project No. 2000624S) and the Czech Technical University in Prague (project No. SGS20/054/OHK1/1T/11). The authors also acknowledge the assistance from the technical staff at the Experimental Centre, Faculty of Civil Engineering, Czech Technical University in Prague.

\section{REFERENCES}

[1] T. Krauthammer. Modern protective structures. CRC Press, Boca Raton, 2008.

[2] M. H. Zhang, V. P. W. Shim, G. Lu, C. W. Chew. Resistance of high-strength concrete to projectile impact. International Journal of Impact Engineering 31(7):825 841, 2005. DOI:10.1016/j.ijimpeng.2004.04.009

[3] R. Sovják, D. Shanbhag, P. Konrád, J. Zatloukal. Response of thin UHPFRC targets with various fibre volume fractions to deformable projectile impact. Procedia engineering 193:3 - 10, 2017. DOI:10.1016/j.proeng.2017.06.179

[4] D. Nicolaides, A. Kanellopoulos, M. Petrou, et al. Development of a new Ultra High Performance Fibre Reinforced Cementitious Composite (UHPFRCC) for impact and blast protection of structures. Construction and Building Materials 95:667 - 674, 2015. DOI:10.1016/j.conbuildmat.2015.07.136.

[5] D. Nicolaides, A. Kanellopoulos, P. Savva, M. Petrou. Experimental field investigation of impact and blast load resistance of Ultra High Performance Fibre Reinforced Cementitious Composites (UHPFRCCs). Construction and Building Materials 95:566 - 574, 2015. DOI:10.1016/j.conbuildmat.2015.07.141.

[6] T. Vavřiník, J. Zatloukal, J. Fornůsek, P. Konvalinka. Numerical analysis of projectile impact on cementitious composite. In AIP Conference Proceedings, vol. 1558, pp. 1012 - 1015. American Institute of Physics, 2013. DOI:10.1063/1.4825675
[7] D.-Y. Yoo, J.-H. Lee, Y.-S. Yoon. Effect of fiber content on mechanical and fracture properties of ultra high performance fiber reinforced cementitious composites. Composite Structures 106:742 - 753, 2013. DOI:10.1016/j.compstruct.2013.07.033

[8] S. Abbas, A. M. Soliman, M. L. Nehdi. Exploring mechanical and durability properties of ultra-high performance concrete incorporating various steel fiber lengths and dosages. Construction and Building Materials 75:429 - 441, 2015. DOI:10.1016/j.conbuildmat.2014.11.017.

[9] J. Smith, G. Cusatis, D. Pelessone, et al. Discrete modeling of ultra-high-performance concrete with application to projectile penetration. International Journal of Impact Engineering 65:13 - 32, 2014. DOI:10.1016/j.ijimpeng.2013.10.008

[10] R. Lovichova, J. Fornusek, M. Mara, et al. The fibre orientation influence in cementitious composite against extreme load resistance. In IOP Conference Series: Materials Science and Engineering, vol. 307, p. 012069. IOP Publishing, 2018. DOI:10.1088/1757-899X/307/1/012069.

[11] P.-C. Aïtcin. High performance concrete. CRC Press, 2011.

[12] N. Banthia, F. Majdzadeh, J. Wu, V. Bindiganavile. Fiber synergy in Hybrid Fiber Reinforced Concrete (HyFRC) in flexure and direct shear. Cement and Concrete Composites 48:91 - 97, 2014. DOI:10.1016/j.cemconcomp.2013.10.018

[13] M. Pająk, J. Janiszewski, L. Kruszka. Laboratory investigation on the influence of high compressive strain rates on the hybrid fibre reinforced self-compacting concrete. Construction and Building Materials 227:116687, 2019. DOI:10.1016/j.conbuildmat.2019.116687

[14] P. Máca, R. Sovják, P. Konvalinka. Mix design of UHPFRC and its response to projectile impact. International Journal of Impact Engineering 63:158 163, 2014. DOI:10.1016/j.ijimpeng.2013.08.003

[15] S. Kravanja, R. Sovják. Ultra-high-performance fibre-reinforced concrete under highvelocity projectile impact. Part II. Applicability of prediction models. Acta Polytechnica 58:355 - 364, 2018. 
[16] P. J. Granata, A. Parvin. An experimental study on Kevlar strengthening of beam-column connections. Composite structures 53(2):163 - 171, 2001. DOI:10.1016/S0263-8223(00)00187-2

[17] A. K. Bandaru, S. Patel, Y. Sachan, et al. Mechanical behavior of Kevlar/basalt reinforced polypropylene composites. Composites Part A: Applied Science and Manufacturing 90:642 - 652, 2016. DOI:10.1016/j.compositesa.2016.08.031.

[18] S. G. Kim, J. K. Park, D. J. Kim. Direct tensile responses of aramid fiber reinforced cementitious composites and textile reinforced cementitious composites with $3 \mathrm{D}$ spacer fabric at high strain rates. Construction and Building Materials 168:232 - 243, 2018. DOI:10.1016/j.conbuildmat.2018.02.136

[19] P. Máca, R. Sovják, T. Vavřiník. Experimental investigation of mechanical properties of UHPFRC. Procedia Engineering 65:14 - 19, 2013. DOI:10.1016/j.proeng.2013.09.004

[20] P. Máca, R. Sovják. Resistance of ultra high performance fibre reinforced concrete to projectile impact. In WIT Transactions on the Built Environment, Structures Under Shock and Impact XII, vol. 126, pp. 261 - 272. 2013. DOI:10.2495/SU120231

[21] S. Kravanja, R. Sovják. Ultra-high-performance fibre-reinforced concrete under high-velocity projectile impact. Part I. Experiments. Acta Polytechnica 58(4):232 - 239, 2018. DOI:10.14311/AP.2018.58.0232.
[22] R. Sovjak, T. Vavřiník, J. Zatloukal, et al. Resistance of slim UHPFRC targets to projectile impact using in-service bullets. International Journal of Impact Engineering 76:166 - 177, 2015.

DOI:10.1016/j.ijimpeng.2014.10.002

[23] S. Kravanja, R. Sovják, P. Konrád, J. Zatloukal. Penetration resistance of semi-infinite UHPFRC targets with various fiber volume fractions against projectile impact. Procedia engineering 193:112 - 119, 2017. DOI:10.1016/j.proeng.2017.06.193

[24] R. Sovják, T. Vavřiník, M. Frydrỳn, et al. Residual velocity of the non-deformable projectile after perforating the ultra-high performance fibre reinforced concrete. In WIT Transactions on the Built Environment, Structures Under Shock and Impact XIII, vol. 141, pp. 257 - 264. 2014. DOI:10.2495/SUSI140221.

[25] B. P. Kneubuehl (ed.). Wound ballistics: Basics and applications. Springer-Verlag Berlin Heidelberg, 2011.

[26] F. Vossoughi, C. P. Ostertag, P. J. M. Monteiro, G. C. Johnson. Resistance of concrete protected by fabric to projectile impact. Cement and Concrete Research 37(1):96 - 106, 2007. DOI:10.1016/j.cemconres.2006.09.003 